\title{
Developing injury indicators for First Nations and Inuit children and youth in Canada: a modified Delphi approach
}

\section{Pike, PhD (1, 2, 3); R. J. McDonald, PhD (3, 4); S. Piedt, BA (2, 3); A. K. Macpherson, PhD (3, 5)}

This article has been peer reviewed.

Tweet this article

\section{Abstract}

Introduction: The purpose of this research was to take the initial step in developing valid indicators that reflect the injury issues facing First Nations and Inuit children and youth in Canada.

Methods: Using a modified-Delphi process, relevant expert and community stakeholders rated each indicator on its perceived usefulness and ability to prompt action to reduce injury among children and youth in indigenous communities. The Delphi process included 5 phases and resulted in a refined set of 27 indicators.

Results: Indicators related to motorized vehicle collisions, mortality and hospitalization rates were rated the most useful and most likely to prompt action. These were followed by indicators for community injury prevention training and response systems, violent and inflicted injury, burns and falls, and suicide.

Conclusion: The results suggest that a broad-based modified-Delphi process is a practical and appropriate method, within the OCAP ${ }^{\mathrm{TM}}$ (Ownership, Control, Access and Possession) principles, for developing a proposed set of indicators for injury prevention activity focused on First Nations and Inuit children and youth. Following additional work to validate and populate the indicators, it is anticipated that communities will utilize them to monitor injury and prompt decisions and action to reduce injuries among children and youth.

Keywords: First Nations, Inuit, indigenous populations, injury indicators, modifiedDelphi technique, surveillance

\section{Introduction}

Injury has been recognized as an important health problem, one that strikes particularly hard at the most vulnerable peoplechildren, youth, seniors and indigenous populations. ${ }^{1}$ Injury is the leading cause of death among Canadian children, youth and young adults-a situation particularly important to indigenous First Nations and Inuit communities as more than $50 \%$ of their populations are under 25 years of age.

Injury is by far the greatest source of potential years of life lost (PYLL) among First Nations* populations. At almost 3.5 times the national average, injury accounts for $26 \%$ of deaths among First
Nations, compared with $6 \%$ of deaths overall in Canada. ${ }^{2,3}$ The injury rates among indigenous teens are almost 4 times greater than those of non-indigenous Canadians, and First Nations male and female youth are, respectively, 5 to 7 times more likely to die of suicide than their peers in other populations. ${ }^{1,4}$ Hospitalization rates due to injury are also significantly higher (twice the rate) for children and youth living in areas with a high percentage of indigenous residents compared to those living in areas with a low percentage of indigenous residents. ${ }^{5}$

To begin to address these injury disparities, respectful approaches that are collaborative, sustainable and culturally sensitive and that reflect the unique identities of First Nations and Inuit peoples are recommended. $^{2,6}$ In 2004, the Canadian Child and Youth Health Coalition listed injury prevention/trauma as one of the theme areas to establish Canadian infant, child and youth health indicators. ${ }^{7}$ Despite this, Canada had fallen behind comparable countries in many of the key health indicators for children and youth. ${ }^{8} \mathrm{~A}$ 5-year injury prevention strategic plan indicated the need to identify injury prevention programs and strategies within Inuit communities and establish an integrated surveillance system to measure injury trends. ${ }^{9}$ And, while the First Nations Regional Longitudinal Health Survey gathers valuable individual and community information in Canada, some of which is

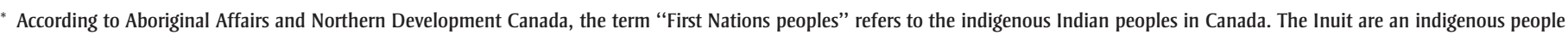
who live mainly in Nunavut, Northwest Territories, Northern Quebec and Northern Labrador.

Author references:

1. Department of Pediatrics, Faculty of Medicine, University of British Columbia, Vancouver, British Columbia, Canada

2. B.C. Injury Research and Prevention Unit, Child and Family Research Institute, B.C. Children's Hospital, Vancouver, British Columbia, Canada

3. First Nations and Inuit Children and Youth Injury Indicators Working Group*

4. Katenies Research and Management Services, Akwesasne Mohawk Territory, Cornwall, Ontario, Canada

5. School of Kinesiology and Health Science, Faculty of Health, York University, Toronto, Ontario, Canada

${ }^{*}$ Collaborating Members of the First Nations and Inuit Children and Youth Injury Indicators Working Group: Geri Bailey (Pauktutiit Inuit Women of Canada), Shelley Cardinal (Canadian Red

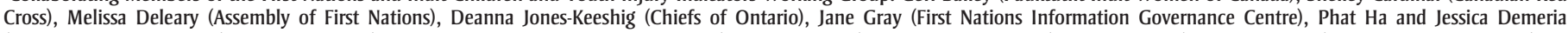

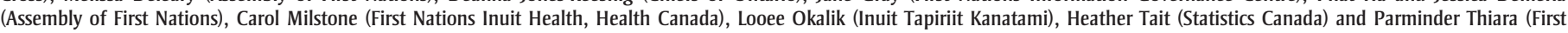
Nations Inuit Health, Health Canada).

Correspondence: Shannon Piedt, B.C. Injury Research and Prevention Unit, F508-4480 Oak Street, Vancouver, BC V6H 3V4; Tel.: 604-875-2000 ext. 5478; Fax: 604-875-3569;

Email: spiedt@cw.bc.ca 
focused on injury, no systematic gathering of comprehensive injury information currently takes place across the country for First Nations children and youth.

The purpose of this research was to take the initial step to develop valid indicators reflective of the injury issues facing First Nations and Inuit children and youth in Canada. The research builds upon the initial work of the Canadian Injury Indicators Development Team, a group of national injury prevention researchers, practitioners and policy makers who established national injury indicators for Canadian children and youth. ${ }^{10}$ Cryer $^{11, p .3-1}$ defined an injury indicator as ".... a summary measure which denotes or reflects, directly or indirectly, variations and trends in injury, or injury-related or an injury control-related phenomenon." The specific aims of our present study were 1) to develop a strong collaborative working group of individuals and agencies representing indigenous peoples, and 2) to develop and specify a suite of valid indicators that can provide a baseline for First Nations and Inuit communities to document, analyze and report child and youth injury data. Once the indicators are populated with data, the resulting information can be used to support community injury prevention decision-making and action planning. Tracked over time, these indicators can show how a community or group's injury profile has changed. ${ }^{12}$

An indicator is valid when it measures what it is presumed to measure. ${ }^{13}$ The indicators in this study were developed based upon the work of the International Collaborative Effort on Injury Statistics (ICE) ${ }^{11}$ in 2001 and subsequent work by Cryer et al. ${ }^{14}$ that outlined criteria for indicator validity. These criteria suggest that an ideal indicator for injury cases should

- have a case definition based on diagnosis-on anatomical or physiological damage;

- focus on serious injury;

- have, as far as possible, unbiased case ascertainment;

- be derived from data that are representative of the target population;

- be based on existing data systems (or it should be practical to develop new data systems that would feed into it); and

- be fully specified in writing.

\section{Methods}

In early 2007, the First Nations and Inuit Health Branch, Health Canada invited the Canadian Injury Indicators Team to begin a 3-year project to develop injury indicators for First Nations and Inuit children and youth. In Canada, First Nations and Inuit peoples are represented by many local, regional and national indigenous agencies as well as the federal government departments whose responsibility it is to ensure the provision of health and social programs, including initiatives to reduce injury.

From the outset, the process and methods of this project sought to balance scientific rigour and a community-oriented approach consistent with the $\mathrm{OCAP}^{\mathrm{TM}}$ principles underlying the collection of indigenous peoples' data and information in Canada. That is, the data are $\underline{\text { Owned, }}$ Controlled, Accessed and Possessed by the indigenous community. ${ }^{15}$ Briefly, the process attempted to ensure a practical approach to injury indicator development.

The First Nations and Inuit Health Branch, Health Canada identified relevant participants in this research and therefore included representatives from the Assembly of First Nations, Inuit Tapiriit Kanatami, Royal Canadian Mounted Police, Indian and Northern Affairs Canada, the SMARTRISK Foundation, Children's Hospital of Eastern Ontario, Plan-It-Safe Program, Katenies Research and Management Services, Statistics Canada, Nunatsiavut Department of Health and Social Development and Pauktuutit Inuit Women of Canada. Twenty-one participants from these agencies came together to plan the project and commence the process; together they formed the First Nations and Inuit Child and Youth Injury Indicators Project Working Group.

A multi-phase modified-Delphi research design was adapted from the methods described by Lindsay et al. ${ }^{16}$ and applied to the development of injury indicators for First Nations and Inuit children and youth. The choice of each indicator was based on limited available data and information describing the burden of injury on First Nations and Inuit children and youth, previous prevention research and best practices and ongoing input from expert
Working Group members and their respective networks.

\section{Phase I: Literature review}

Phase I included a review of the relevant literature, with the goal of identifying any previously established valid and evidencebased First Nations and Inuit child and youth injury indicators. Research analysts at the First Nations and Inuit Health Branch, Health Canada conducted the literature review based upon the methodology used by Pike et al. ${ }^{10}$ using the following databases for the period 1985 to 2007, inclusive: Medline, Ovid, Transport, Transportation Research Information Services, Sportdiscus, Cumulative Index to Nursing and Allied Health Literature, Embase, Psychinfo, Healthstar and Hispanic American Periodicals Index. The search also included indigenous agency and government websites and program report listings as a means of accessing relevant grey literature. The research analysts identified and summarized a total of 10 studies from the peerreviewed and grey literature (list available from the authors upon request). The review of literature revealed an initial list of 48 injury indicators.

\section{Phase II: Establishing important injury categories and ranking injury indicators}

Of the 21-member Working Group, 19 were able to meet and agree on 4 areas in which to group child and youth injury indicators relevant to First Nations and Inuit communities: workplace, home and public safety; transport; sport and recreation; and inflicted injury / violence (including self-inflicted injury). Using their expertise, personal experience and knowledge of the research, the group discussed the most common injuries within each area and a way to potentially measure and monitor those injuries. As a result, 4 types of indicators were defined and described: outcome, risk and protective factors, program and policy.

The group then divided into small groups based on the 4 injury areas and reviewed the 48 indicators suggested by the literature review, adding additional indicators where deemed appropriate. Following full review and discussion, each small group presented their list of indicators to the 
large group. All in all, the list included 170 indicators.

With the goal of reducing the number of indicators while retaining those considered important and reflective of the community child and youth injury issues, the Working Group undertook another exercise to prioritize the indicators. In this exercise, the list of indicators was posted on flip charts. Participants were each given 55 paper adhesive dots (approximately one-third the number of the posted indicators) and instructed to position these beside those indicators they considered the most important. All indicators that were marked with 10 or more dots (representing an initial indication of importance) were retained and the remainder rejected. This N/3 technique of prioritizing $^{17}$ resulted in a list of 62 indicators that were regrouped by the participants from the original 4 into 7 broad injury categories: all injury areas; animal bites and hypothermia / frostbite; violent/inflicted injury; burns and falls; drowning; suicide; and motorized vehicle collisions.

The criteria used to inform priority setting included choosing injury indicators that 1) reflected a significant burden to First Nations and Inuit peoples, their families and the health care system, and 2) could be acted upon through prevention initiatives. Further, the participants were provided the International Collaborative Effort Injury Indicators Group (ICEIInG) criteria for indicator validity to inform their decision-making.

The subsequent step was to review and further refine the list of 62 indicators. Working Group members were asked to consult with their constituent groups and, for each indicator, recommend whether to "keep" or "let go" of it or whether they were "unsure" based upon 3 criterion questions: 1) Is this indicator important in your community? 2) Would this indicator help you to track injuries in your community? 3) Does this indicator give you sufficient information to take action to prevent injuries among children and youth in your community?

We reviewed the responses and retained those indicators that a majority of the
Working Group had recommended keeping. Indicators that received a majority of "let go" responses were dropped. (No indicators received a majority vote of "unsure.") During this phase of the process and as a result of discussion among themselves, Working Group members proposed 2 additional indicators, which were circulated and judged to be important enough to keep: the percentage of children/youth enrolled in "learn to swim" programs and percentage of violent offenders participating in restorative justice programs were included as additional potential indicators, resulting in a list of 36 injury indicators at this stage.

\section{Phase III: Regional feedback}

Further input was sought from potential users at the community level. Investigators attended regional meetings and engaged First Nations and Inuit injury prevention practitioners and decision makers. At each meeting, the project was explained and participants were asked for their feedback on the list of 36 child and youth injury indicators.

Feedback on each injury indicator was obtained from a number of regional organizations in Alberta, Manitoba, Ontario, Quebec and Nunatsiavuut: the Manitoba Community Wellness Working Group, the Assembly of First Nations Regional Injury Prevention Working Group, the First Nations Early Childhood Circle (representatives from Saskatchewan Aboriginal Head Start Initiative and Federation of Saskatchewan Indian Nations), Chiefs of Ontario and the National Inuit Council on Health.

In this phase of the process, regional agency representatives identified 7 additional indicators judged to be important in understanding and preventing child and youth injury in their communities. As a consequence, the list of potential injury indicators increased from 36 to 43 .

\section{Phase IV: Specification of indicators}

We created a standard template for indicator specification (see Table 1) and developed
TABLE 1

Template for the specification of child and youth injury indicators

\begin{tabular}{l} 
Indicator \\
\hline Definition \\
Definition of relevant terms \\
Justification for this indicator \\
Operational definition of a case \\
Method of calculation \\
Numerator \\
Denominator \\
Data sources, availability and quality/years \\
represented \\
Units of measurement \\
Guide for use \\
Scope of indicator \\
Specification of data needed \\
Limitations \\
How to use this indicator \\
\hline
\end{tabular}

draft specifications for the 43 indicators based upon the format for previous reports from Australia, ${ }^{18}$ New Zealand, ${ }^{19}$ Europe $^{20}$ and Canada. ${ }^{21}$ The Working Group then met to discuss, revise and refine the indicators and their specifications, and an additional round of review and further feedback was accomplished via email. Nine members of the Working Group responded ${ }^{\dagger}$ and recommended that several indicators be dropped due to the lack of available data and the difficulty and cost associated with generating new data collection systems to populate those indicators. Phase IV resulted in a further refined list of 33 candidate injury indicators (see Table 2).

\section{Phase V: Finalizing injury indicators}

Following the specification of all 33 indicators, the Working Group met for the last time in December 2008 with 13 members attending. Each indicator was rated for perceived usefulness and ability to prompt action to reduce injuries among First Nations and Inuit children and youth using a 9-point scale, with 1 being low (not useful, not actionable) and 9 being high (very useful, very actionable). This resulted in 7 indicators being judged as neither useful nor actionable (and therefore not meeting the criteria for validity), either because of lack of data and/or resources availability, and

\footnotetext{
$\dagger$ It is likely there were so few responses due to the length of the document and the time required to review it and/or satisfaction with the list of indicators and specifications.
} 
TABLE 2

Ratings of usefulness and ability to prompt action of First Nations and Inuit child and youth injury indicators

\begin{tabular}{|c|c|c|c|}
\hline $\begin{array}{l}\text { Indicator } \\
\text { domain/area }\end{array}$ & Indicator & $\begin{array}{l}\text { Usefulness mean } \\
\text { (SD) rating [1-9] }\end{array}$ & $\begin{array}{l}\text { Prompt action mean } \\
\text { (SD) rating [1-9] }\end{array}$ \\
\hline \multirow[t]{4}{*}{ Across all injury areas } & $\begin{array}{l}\text { Mortality rate: number of deaths per } 10000 \text { children and youth due to each } \\
\text { type of injury }\end{array}$ & $9.00(0.0)$ & $8.11(1.5)$ \\
\hline & $\begin{array}{l}\text { Number and proportion of self-reported alcohol, solvent and substance use among } \\
\text { First Nations children and youth (based on RHS data) }\end{array}$ & $6.63(1.8)$ & $6.44(2.1)$ \\
\hline & Number of self-governing features that exist in the community & $6.78(2.7)$ & $6.11(3.0)$ \\
\hline & Potential years of life lost (PYLL) due to injury among children and youth ${ }^{\mathrm{a}}$ & $\mathrm{n} / \mathrm{a}$ & $\mathrm{n} / \mathrm{a}$ \\
\hline \multirow{2}{*}{$\begin{array}{l}\text { Community injury } \\
\text { prevention training/ } \\
\text { response systems }\end{array}$} & Proportion of community members who complete injury prevention training & $7.11(1.3)$ & $6.33(1.4)$ \\
\hline & $\begin{array}{l}\text { Presence of a community emergency preparedness plan (i.e. flooding, fires, } \\
\text { blizzards, earthquakes, etc.) }\end{array}$ & $7.78(1.2)$ & $7.44(1.1)$ \\
\hline \multirow[t]{2}{*}{ Animal bites } & $\begin{array}{l}\text { Rate of injuries due to animal bites and maulings per } 10000 \text { children and youth } \\
\text { in a community }\end{array}$ & $8.44(0.9)$ & $7.67(1.9)$ \\
\hline & Number and proportion of communities with Animal Control Services & $7.25(1.3)$ & $6.50(2.2)$ \\
\hline Hypothermia/Frostbite & Rate of hypothermia or frostbite per 10000 children and youth & $7.25(1.4)$ & $5.63(2.2)$ \\
\hline \multirow[t]{3}{*}{ Violent/inflicted injury } & $\begin{array}{l}\text { Number and proportion of police calls and charges related to violent injury } \\
\text { per } 10000 \text { children and youth }\end{array}$ & $8.33(0.9)$ & $7.56(0.4)$ \\
\hline & $\begin{array}{l}\text { Self-reported rate of inflicted injury (violence and abuse) per } 10000 \text { children and } \\
\text { youth (not including self-inflicted injuries) }\end{array}$ & $7.78(1.1)$ & $7.00(1.3)$ \\
\hline & $\begin{array}{l}\text { Number and proportion of violent offenders participating in restorative justice } \\
\text { programs }\end{array}$ & $5.00(3.2)$ & $5.00(3.0)$ \\
\hline \multirow{4}{*}{ Drowning } & $\begin{array}{l}\text { Number and proportion of communities with access to water safety } \\
\text { education/programs }\end{array}$ & $7.89(1.3)$ & $7.22(0.8)$ \\
\hline & Enforcement of laws related to water & $5.13(2.5)$ & $4.63(2.2)$ \\
\hline & $\begin{array}{l}\text { Number and proportion of children and youth who drown each year, including type } \\
\text { of body of water and circumstances }\end{array}$ & $8.56(0.7)$ & $7.33(1.0)$ \\
\hline & $\begin{array}{l}\text { Number and proportion of children and youth enrolled in "learn to swim" programs } \\
\text { in a specific year }\end{array}$ & $7.67(1.0)$ & $6.50(1.2)$ \\
\hline \multirow[t]{4}{*}{ Suicide } & Number of communities with mental health and wellness promotion programs & $6.50(2.8)$ & $6.86(2.3)$ \\
\hline & Rate of self-reported poor mental health among children and youth & $7.89(0.8)$ & $6.56(1.9)$ \\
\hline & $\begin{array}{l}\text { Rate of suicide attempts/self-harm and completed suicides per } 10000 \text { children } \\
\text { and youth }\end{array}$ & $8.78(0.4)$ & $7.44(1.0)$ \\
\hline & Rate of calls to suicide prevention crisis telephone services, by geographical region & $7.67(1.0)$ & $7.22(0.8)$ \\
\hline
\end{tabular}

Continued on the following page 
TABLE 2 (continued)

Ratings of usefulness and ability to prompt action of First Nations and Inuit child and youth injury indicators

\begin{tabular}{|c|c|c|c|}
\hline $\begin{array}{l}\text { Indicator } \\
\text { domain/area }\end{array}$ & Indicator & $\begin{array}{l}\text { Usefulness mean } \\
\text { (SD) rating [1-9] }\end{array}$ & $\begin{array}{l}\text { Prompt action mean } \\
\text { (SD) rating [1-9] }\end{array}$ \\
\hline \multirow[t]{7}{*}{ Motorized vehicle collisions } & $\begin{array}{l}\text { Rate of motorized vehicle collisions involving children and youth, by type of vehicle } \\
\text { and crash circumstances }\end{array}$ & $8.78(0.4)$ & $8.00(1.0)$ \\
\hline & $\begin{array}{l}\text { Number and proportion of seriously injured children and youth occupants who were } \\
\text { unrestrained (not wearing a seatbelt) in a motor vehicle collision }\end{array}$ & $8.67(0.5)$ & $8.22(1.4)$ \\
\hline & $\begin{array}{l}\text { Number and proportion of youth who enrolled in and completed driver education } \\
\text { courses-skills for car, snowmobile, boat and ATV drivers }\end{array}$ & $8.22(0.7)$ & $7.22(1.0)$ \\
\hline & $\begin{array}{l}\text { Proportion of motor vehicles demonstrating proper use of child vehicle restraints } \\
\text { (car seats) and booster seats by community }\end{array}$ & $8.78(0.4)$ & $8.33(1.0)$ \\
\hline & $\begin{array}{l}\text { Age and sex of drivers and occupants involved in motor vehicle crashes by vehicle } \\
\text { type (car, van, truck, ATV, snowmobile) and road user (driver, passenger, } \\
\text { pedestrian, cyclist) }\end{array}$ & $8.33(0.9)$ & $7.67(1.4)$ \\
\hline & $\begin{array}{l}\text { Presence of legislation of minimum age to drive an ATV. Number of provinces and } \\
\text { territories with legislation of minimum age to drive an ATV }\end{array}$ & $7.13(2.2)$ & $6.00(2.7)$ \\
\hline & $\begin{array}{l}\text { Number and proportion of seriously injured or killed children and youth not wearing } \\
\text { a helmet while riding ATVs, snowmobiles and/or bicycles by community }\end{array}$ & $8.67(0.5)$ & $8.11(0.9)$ \\
\hline
\end{tabular}

Abbreviations: ATV, all-terrain vehicle; PYLL, potential years of life lost; RHS, First Nations Regional Longitudinal Health Survey; SD, standard deviation.

Note: The dark grey shaded areas represent indicators that received low ratings and were subsequently dropped.

${ }^{a}$ All members of the expert group were unanimous in their agreement to include PYLL as a useful indicator and did not rate it.

were dropped (see the shaded indicators in Table 2). The process concluded with the Working Group endorsing a final list of 27 injury indicators for First Nations and Inuit children and youth.

Immediately following the rating process, the group unanimously agreed to re-insert PYLL due to injury, which had been listed at the review of literature stage, although they did not rate it.

\section{Results}

The modified-Delphi method resulted in a proposed list of 27 injury indicators. Indicators related to motorized vehicle collisions, mortality rates and the number of children and youth hospitalized due to each injury type ranked highest in terms of usefulness and ability to prompt action. These were followed by community injury prevention training and response systems, violent and inflicted injury, burns and falls, and suicide although some were rated somewhat lower in terms of their ability to prompt action.

\section{Discussion}

This modified-Delphi approach represents the first step in the indicator development process that resulted in a final proposed set of 27 First Nations and Inuit child and youth injury-related indicators that can be used to inform injury prevention in Canada's indigenous peoples. While there was some variation in the degree to which experts rated the usefulness and likelihood to prompt action of each indicator, there was general consistency and agreement. The high scores given to the injury indicators suggest that they capture the needs of those working to prevent injuries among First Nations and Inuit children and youth.

While the indicators were developed to apply to First Nations and Inuit children and youth, some indicators are applicable to any children and youth living in rural or remote communities, and others apply to all children and youth.

\section{Strengths and limitations}

There are some limitations to this work, which are important to highlight here.

First, there is a paucity of published literature related to indigenous child and youth injury prevention to inform the decision-making around the indicator selection.

Second, the modified-Delphi process technique used is subjective and based upon participant expertise and experience. While efforts to be objective in generating and prioritizing indicators were made within the process, the results depend upon the opinions of the participating experts. Participants were advised of the criteria for indicator validity, but it is not known how much that influenced their choice of indicators. It is possible that the results would be different had a different group of experts participated. However, the experts chosen were those deemed most relevant to the process because they were knowledgeable about the field and the best representatives of their agencies and constituents.

A further limitation is the current and continuing lack of the data necessary to populate the indicators. Some indicators had no data available, and may not have in the foreseeable future. However, data for many of the indicators are available from the First Nations Regional Longitudinal Health Survey, and some communities (e.g. 10 bands of the Secwepemc Nation in British Columbia) collect health and injury data that can populate the indicators. In addition, we anticipate that, with time, more communities will gather their own data and information of local interest and relevance to child and youth injury prevention. This approach is consistent with the OCAP $^{\mathrm{TM}}$ principles. $^{15}$ 


\section{Conclusion}

Using a systematic, interdisciplinary modified-Delphi method, which involved direct input and leadership from First Nations and Inuit experts, this study resulted in a proposed list of 27 useful and actionable injury indicators to guide First Nations and Inuit community injury prevention initiatives focused on children and youth.

While several of the indicators are in line with those developed for non-indigenous Canadian children and youth, ${ }^{10}$ differences do exist. Most important, the current indicators are specific to injury among First Nations and Inuit children and youth, reflecting local circumstances and conditions important to injury risk and prevention in indigenous communities, some of which are small, rural and remote. For example, the First Nations and Inuit indicators included those that relate to community injury prevention training and response systems, animal bites, drowning, hypothermia and frostbite, which were considered less important for non-indigenous populations.

Further research and collaboration by the Working Group with indigenous communities will demonstrate the utility of the indicators in furthering injury prevention. Work will continue to identify the necessary appropriate data and information to populate the indicators. It is anticipated that the research team will work with communities to gather the necessary data and information to populate the indicators, including helping develop consistent definitions of causes of injury and injury severity. Ultimately, indigenous health authorities and communities can use the information to plan, implement and evaluate programs and initiatives to prevent injury among children and youth, consistent with the $\mathrm{OCAP}^{\mathrm{TM}}$ principles underlying research among Canadian indigenous communities.

\section{Acknowledgements}

Funding for this study was provided by the First Nations and Inuit Health Branch at Health Canada (FNIHB), the BC Child and Youth Health Research Network
(CYHRNet) and the Canadian Institutes of Health Research (KTB-109190).

The authors wish to acknowledge all members of the First Nations and Inuit Child and Youth Injury Indicators Working Group for their contribution to this research. We would like to acknowledge the First Nations and Inuit Health Branch, Health Canada (FNIHB) and the BC Child and Youth Health Research Network (CYHRNet) for providing the funds to conduct this study and for their support in ensuring timely access to essential resources. In addition, we wish to thank the Assembly of First Nations (AFN), Inuit Tapiriit Kanatami (ITK), Pauktuutit Inuit Women of Canada and the Canadian Institutes of Health Research. We are most grateful to these organizations for the important resources provided and for their ongoing support to facilitate the process of refining our final list of indicators. We also wish to thank the Manitoba Community Wellness Working Group, the AFN First Nations Regional Injury Prevention Working Group, the First Nations Early Childhood Circle (representatives from the Saskatchewan Aboriginal Head Start Initiative and Federation of Saskatchewan Indian Nations), the Chiefs in Ontario, the AFN Health Officers Council, the representatives of the First Nations Regional Longitudinal Health Survey and the National Inuit Committee on Health for their input during the process of determining and refining the list of indicators.

\section{References}

1. SMARTRISK. Ending Canada's invisible epidemic: a strategy for injury prevention. Toronto (ON): SMARTRISK; 2005.

2. Banerji A; Canadian Paediatric Society; First Nations, Inuit and Métis Health Committee. Preventing unintentional injuries in Children and Youth in Canada. Paediatr Child Health. 2012;17(7):393-4.

3. Health Canada. A statistical profile on the health of First Nations in Canada: Health services utilization in Western Canada, 2000 [Internet]. Ottawa (ON): Health Canada; 2009 [cited 2012 Apr 15]. Available from: http://www.hc-sc.gc.ca /fniah-spnia/pubs/aborig-autoch/2009-stats -profil-vol2/index-eng.php
4. Harrop AR, Brant RF, Ghali WA, Macarthur C. Injury mortality rates in Native and nonNative children: a population-based study. Public Health Rep. 2007;122(3):339-46.

5. Oliver LN, Kohen DE. Unintentional injury hospitalizations among children and youth in areas with a high percentage of Aboriginal identity residents: 2001/2002 to 2005/2006. Health Rep. 2012;23(3):7-15. [Statistics Canada, Catalogue No.: 82-003$\mathrm{XPE}]$.

6. Anderson M, Smylie J, Anderson I, Sinclair R, Crengle S. First Nations, Métis, and Inuit health indicators in Canada: a background paper for the project "Action Oriented Indicators of Health and Health Systems Development for Indigenous Peoples in Australia, Canada, and New Zealand" [Internet]. 2006 [cited 2013 Apr 15]. Available from: http://www.med.uottawa .ca/SIM/data/Images/Aboriginal_health_ indicators.pdf

7. Canadian Child and Youth Coalition. Our work: health indicators: child \& youth health indicator program [Internet]. London (ON): CCYHC; 2008 [cited 2013 Apr 12]. Available from: http://www.ccyhc .org/work_indicators_about.html

8. Leitch K. Reaching for the top: a report by the advisor on healthy children \& youth. Ottawa (ON): Government of Canada; 2007.

9. Pauktuutit. Inuit Five-Year Injury Prevention Strategic Plan 2010-1015. Ottawa (ON): Pauktuutit Inuit Women of Canada; 2010.

10. Pike I, Piedt S, Warda L, et al. Developing injury indicators for Canadian children and youth: a modified-Delphi approach. Inj Prev. 2010;16:154-60.

11. Cryer C. ICE Injury Indicators Group (ICEIInG) - progress report, aspirations, goals and strategy development. In: International Collaborative Effort on Injury Statistics, Volume IV. Washington (DC): NCHS, CDC, US Department of Health and Human Services; 2003. Available from: http://www. cdc.gov/nchs/data/ice/iceproceedings.pdf

12. First Nations Centre. Understanding health indicators. Ottawa (ON): National Aboriginal Health Organization; 2007. 
13. Guilford JP, Fruchter D. Fundamental statistics in psychology and education, 5th edition. New York: McGraw-Hill; 1973.

14. Cryer C, Langley JD, Jarvis SN, Mackenzie SG, Stephenson SC, Heywood P. Injury outcome indicators: the development of a validation tool. Inj Prev. 2005;11:53-7.

15. First Nations Information Governance Centre. The First Nations principles of $\mathrm{OCAP}^{\mathrm{TM}}$ [Internet]. Akwesasne (ON): FNIGC; 2013 [cited 2013 Aug 19]. Available from: www.fnigc.ca/ocap.html

16. Lindsay P, Schull M, Bronskill S, Anderson $\mathrm{G}$. The development of indicators to measure the quality of clinical care in emergency departments following a modifieddelphi approach. Acad Emerg Med. 2002;9: 1131-39.

17. Andersen A. A process guidebook: tools and techniques for effective facilitation. Chicago (IL): Arthur Andersen \& Co; 1991.

18. Harrison JE, Steenkamp M. Technical review and documentation of current NHPA injury indicators and data sources. Injury Research and Statistics Series Number 14. Adelaide (AU): AIHW; 2002. AIHW Catalogue No.: INJCAT 47.

19. Cryer C, Langley J, Stephenson S. Developing valid injury outcome indicators: a report for the New Zealand Injury Prevention Strategy. Dunedin (NZ): Injury Prevention Research Unit, Department of Preventive and Social Medicine, University of Otago; 2004

20. Pencheon D. The good indicators guide: understanding how to choose and use indicators. Coventry (UK): NHS Institute for Innovation and Improvement; 2008.

21. Canadian Institute of Health Information. Pan-Canadian primary health care indicators. Report 1, Volume 1: Pan-Canadian Primary Health Care Indicator Development Project [Internet]. Ottawa (ON): Canadian Institute for Health Information; 2006 [cited 2013 Apr 19]. Available from: https://secure.cihi.ca /free_products/PHC_Indicator_Report_1_ Volume_1_Final_E.pdf 